\title{
The Use of Artificial Intelligence in Building Automated Trading Systems
}

\author{
Jan Juricek
}

\begin{abstract}
This paper deals with the use of artificial intelligence to improving the results of automated trading systems on stock markets. The article introduces the reader with the concept of long term success in trading in financial markets. It defines general fundamental and mainly technical approach of building automated trading system as well as its components, risk management, entry and exit strategy and money management. This work is focusing on systematical approach and components. It summarizes the findings of systemic approaches over building trade system and an application of the AI (mainly genetic algorithms and neural networks) to find the best solutions, while the use of artificial intelligence principles gives traders a powerful tool in building robust trading systems.
\end{abstract}

Index Terms-Artificial intelligence, stock trading, trading system, automation.

\section{INTRODUCTION}

For much of the general public, is a professional stock trading a domain of highly skilled financial analysts, multinational financial corporations, private equity bankers and banks with adequate computing potential. But also individuals are now starting to pay more attention on trading on world markets - these solitaires operators with small capital; entities completely independent of banking houses or "hedge" funds and market makers [1]. This is mostly due to technological advances of our time - the availability of IT for IT operations, constant internet connection (VPS solutions on the backbone network), business and testing tools based on modern technologies (use of multiple CPU cores, programming "easy-language") and optimization software. Availability of the information technology equipment provides individuals with large computational potential. This potential can be used in the overall automation of business practices and procedures.

This work aims to familiarize the reader with the progress of construction of automatic trading systems and application possibilities of artificial intelligence elements in their construction and improvement.

\section{General APPROACHES TO StOck TRAding}

\section{A. Long Term Success}

The key point of the success of the independent investor (can be defined as speculator) is to be in the long-term profit on the market. Stock trading is not trivial, even though it is possible to achieve short-term high profits by chance [2]. This

Manuscript received November 10, 2013; revised January 16, 2014.

Jan Juricek is with the Department of System Analyses, University of Economics in Prague, Czech Republic (email: jan.juricek@vse.cz). coincidence can be defined as:

1) The market moved without apparent cause, towards an advantageous position of a trader, this cause was not foreseen.

2) A movement of the market occurred without cause and without prior assessment of entry into the market by a trader.

It is obvious that for further investigation coincidences should be eliminated. Consistently profitable trading requires a lot of time, effort and most importantly endurance. Therefore, only a small percentage of traders are in long term profit on the market. Shreiner [3] defines the main reasons for failure in the absence of formalized rules of the stock exchange - trading system, failure of the system, inadequate testing, poor risk-management and re-optimization. As stated, losses are resulting from the incosistent approach and in violation of (or absence) of any of fixed procedures (plans). It is clear that the psyche very intensively influence every human behavior. But not the program, acting as defined instructions. Together with other advantages - a considerable saving of time (testing, execution of business transactions, waiting for the trade signal), the stock exchange traders popularize automated trading systems, performing these procedures automatically without human intervention.

\section{B. Trading Systems in Stock Market}

When you submit your final version, after your paper has been accepted, prepare it in two-column format, including figures and tables.

A design of a business system (trading system) can be approached in two ways:

1) The fundamental approach - trades are placed by analysis of economic performance, by historical interpretation and acceptance of the results of the financial market, by financial indicators traded media (substrate - such as shares), by the mood on the trading markets and the overall fiscal and monetary data traded region [4].

2) The technical approach - a trader creates a trading system based on solid technical indicators (indicators), readable directly on the chart, a system which do not allow the substrate, respectively, are not taken into account fundamental news or market sentiments.

In further research of construction of a trading system, technical approach will be focused. Technical approach can be distinguished by the mechanical and by discretionary. Mechanical system entering the market when absolutely obvious (clear) fulfilled conditions, which are given by indicators - moving averages, oscillators, power trend volality indicators or price patterns. The business plan must also include (as it contains rules for the input) rules for exit from 
the market and "money-management". These conditions are strict in the time of position, immutable and can not be change during the live trade. The discretionary approach includes live (current) individual decisions. The system (and the trader) adapts and bends framework of rules according to the current market behavior.

\section{Technical Approach and the Use of the Automatization}

Trading system is seen as a comprehensive set of proven rules [5] - components. Components in the construction business system are:

1) Entry Strategy - rules for an admission - under what conditions the system clearly entering a trade. Entry strategies may be a crossing indicators, which are a graphical representation of mathematical interpretation of prices in a particular stock market (oscillators, mean (moving, exponential), statistical, etc.)

2) The method of placing and receiving solid losses - it is about managing risk. This defines the maximum loss on a trade and thus eliminate their greater potential losses. The amount of risk is expected to be $1-2 \%$ per trade.

3) An exit strategy from the market. A trader defines the conditions where it emerges from the trade - for example, if they reach a certain profit or changing the parameters of technical indicators in the market, or method of exploring the historical maximum potential profits and losses during the holding of trade.

4) Money-management and management position size

A creation of such complex trading systems must be done systematically. It is necessary to specify in advance the different phases: design - creating a complete system consisting of the above components, testing - verification, optimization of system parameters, evaluation-assessment and evaluation "money-management" and the deployment into the live environment - on the stock market. The stages are shown in the following figure.

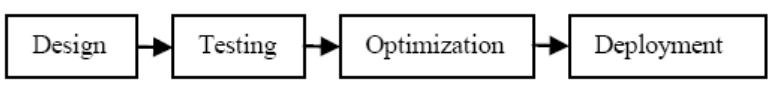

Fig. 1. Complex trading system development stages.

At Design phase, the rules for entries to the market are being designed (indicators, chart patterns, breakouts, price-action entries), as well as the rules for the exits, stop-loss (fixed SL, support/resistences, high/low of the market, average market volatility, etc). At this stage the complex strategy is being designed. At testing phase, a trader is testing the strategy in the particular market condition and trading hours. There must be the in-sample (backtesting) and out-of-sample data for the forward testing. Maximal drawdown is a point of study. At optimitation phase, an overall optimization of the system / strategy is being done. Critical point is maximal loss and maximal profit during the open position of a trade. At deployment phase, risk management is taking place as well as day-to-day monitoring of the system performance.

\section{APPLICATION OF ARTIFICIAL INTELLIGENCE (AI) IN STOCK TRADING}

\section{A. AI}

The use of artificial intelligence in building automated trading systems, according to the definition of artificial intelligence itself [6] deals with the creation of machines machines, showing signs of intelligent behavior. In relation to the stock trading, the two directions can be proceeded: intelligent behavior, from the above definition, can be regarded as trading by human reason - based on experience (see below neural networks). The second direction can then be AI application of principles in the construction of self-sufficient trading system and its consistent improvement. Self-sufficient is understood without the intervention of human factors - influencing behavior - in trading. According to Goldstein [7] is a critical success factor the fact of achieving effective transfer of knowledge to the AI to allow the effective use of AI programs. Result is that prioritization of content and its output of the knowledge is more important than its form. During a construction of machines - ie. Automated trading systems (ATS) it could be primarily used two approaches to solutions in the field of artificial intelligence: genetic programming (specifically genetic algorithms - GA) and neural networks. Genetic programming uses methods similar biological evolution in the creation of computer programs. In the creation of trading systems can be said, therefore, that poor-performing systems (reporting bad trades) are better left disabled / deleted, and good - powerful trading systems let live (earn) and improved or in other words, to constantly adopt changing nature, behavior and factors of the markets.

Neural network is one of the computational models used in artificial intelligence. The pattern is the behavior of the relevant biological structures. Artificial neural network structure is designed for the parallel distributed processing. [6] Neural networks are used among other things for the recognition and anticipation of the time series - in this case a market exchange).

\section{B. The Use of Neural Networks in the Construction of Complex Systems}

Experienced businessmen and traders are determined primarily on the basis of their own experience. These experiences in decision making of the market entries stem from historical data. Today is not a problem to obtain historical data of a specific exchange, index or other financial base, but it is difficult to interpret these data. Now this is the response of a time series analysis - which provides a mathematical description of system behavior, in our case, a description of market development. Mathematical operands in this case are called "ticks" (changes) or temporally time defined in value of opening, closing value, maximum value, minimum value all base on the timeframe provided. The aim of using neural networks is to analyze the historical data - to convert this history to the most perfect mathematical description of the evolution of the market and predict to a certain extent its future development. This model should allow to understand the way of given values and the conditions of operation of these values (in practical terms, this includes the local maxima - minima, correction in the stock market, etc.). Neural networks can be used in such subject area / situation where the problem can not be described mathematically [8]. Artificial neural network was created as a 
structure, and function as a mathematical model of human neural network (includes the brain). This network allows us to learn new things and solve complex tasks [8], [5]. Each artificial network includes input and output layer (or hidden layers) used for the actual calculation and the amount depends on the difficulty of solved tasks.

The largest expansion of the use of neural networks began in the 90s of the last century. The study of scientists Cheng, McClain of 1997 stated that the use of component neural networks is able to create the 1989-1993 average return on investment of $17 \%$ [9]. In addition to this study and long-term monitoring of market bonds and U.S. government bonds, other business analysts had warned that the neural network could achieve with the help of regression analysis even better results. According R. Shardy, leading analyst was nineties The largest expansion of the use of neural networks began in the $90 \mathrm{~s}$ of the last century. The study scientists Cheng, McClain of 1997 stated that the use of component neural networks is able to create the 1989-1993 average return on investment of $17 \%$ [9]. In addition to this study and long-term monitoring of market bonds and U.S. government bonds continue our analysts warning that the neural network achieved with the help of regression analysis, better results. R. Shardy, leading analyst, demonstrated on 30 trials bond better results using a neural network than with traditional analytical methods [10], [11]. But then came "crashes". There were also demonstrated no predictions or models simulating (and anticipating) Asian stock crisis in the late nineties, oil dips and deflation in 1998-1999 and Internet fever on U.S. exchanges (mainly NASDAQ). Leading analysts have tried to disaggregate the market behavior by time series models. Decomposition of time series (see above) is the simplest approach to the modeling of time series [7], [12]. Analysis of the series are very computationally intensive, but can be obtained by decomposition of the parameters that can be easily analyzed. The behavior of market it is possible to decompose the 4 parameters:

1) The trend parameter $(T t)$, which is defined as long-term increasing or decreasing trend in the market - such as economic growth or consistent good underlying asset or commodity (in 2001-2012 gold, etc.).

2) Cyclic parameter $(C t)$ is characterized by long-term cyclical fluctuations trend with a period less than a yearswing.

3) Seasonal parameter (St) is described as a regular deviation from the trend in the same period.

4) Random parameter - irregular short-term fluctuations having a totally random character $(E)$.

The time series $Y t$ (refer to (1)) can be modeled by the sum of the individual parameters:

$$
Y t=T t+C t+S t+E
$$

\section{Genetic Algorithms in Trading}

Genetic algorithm (GA) is a test procedure that seeks the principles by application of evolutionary biology to solve problems for which there is no solution in the current exact algorithms [8], [9], [13]. From the point of view on issue of stock trading and making the automatice trading systems (machines), GA is a tool that helps a lot faster and more efficiently manage the optimization of several variables in the trading system development stage. GA is now basically used in two ways: to design trading systems and advanced optimization. In fact, GA approach itself optimizes each variable in the definition of input and thus combinations are optimized. A trading system contains several points of variables:

1) Indicators for evaluation of parameters to entering the market (place an order).

2) Output parameters to closing the position at the market (solid, flowing); types of outputs.

3) Market timeframe on which trading system is being tested.

These variables produce huge number of combinations. A trader should evaluate and combine all possibilities for best results, which is not possible for millions combinations. When applying GA in the design stage of the trading system development, it can proceed as follows:

1) The initialization of the zero generation of the individuals (individuals are the conditions and the terms by which are we placing the order at the market).

2) Cycle $N=1$; a selection of individuals with great ability adequate performance and profitability on the stock market.

3) The next generation $\{g\}$ of individuals $\{\mathrm{I}\}$ with following options:

a) Crossing - biological specimens swap parts between each other

b) Mutations - random changes of $\{$ I $\}$

c) Reproduction - copy the next generation unchanged

4) Testing of efficiency and profitability.

5) Cycle $N=2$; provided that a defined individual fitness (performace of the trading system) have not been complied.

6) The end for GA: Finding the best solution $\{\mathrm{g}\}$.

GA and its applications to the softwares which allows trading and testing is being engaged in a number of specialized companies. One of the best-managed SW, according to independent sources is Adaptrade builder program [10]. In this specialized software, a trader can define the parameters of the system as such, but also can attach a weight to the specific parameters and also define the size of the population and the number of generations.

\section{CONCLUSION}

The use of artificial intelligence principles gives traders a powerful tool in building robust trading systems. Their applications are governed by professionals and programmers around the world. There are already specialized business software makers, having elements of genetic algorithms built directly into their applications. These algorithms certify the testing and optimization of the parameters of trading systems. In practice, the use of neural networks in the construction of the trading systems (ie mechanized predict market direction) failed to fully acknowledge. Thus, unlike prediction of weather or robust data-mining, neural networks are not used 
in the financial markets. On the other hand, a genetic programming in the professional trading on world stock markets, naturally found huge application. Thus, another point of research is detailed testing of the data selected by specific financial instruments. It is important to emphasize that neither the process of genetic search algorithms is somehow extremely easy. Stock exchange trader must penetrate into the problems and understand at least the base of the elements, design and parts of the algorithms and especially to understand how to test the robustness of strategies. In addition, the calculation can be time consuming, especially if a trader tries to analyze the larger history of intraday data.

\section{REFERENCES}

[1] Burza cenných papírů Praha. (1998-2012). SPAD (Systém pro podporu trhu a akcií). [Online]. Available: http://www.bcpp.cz/obchodovani/SPAD

[2] Randomnes, Wikipedia. [Online]. Available: http://www.en.wikipedia.org/wiki/Randomness

[3] J. Schreiner, "Doors close on 'scam capital' reputation left behind; investors were likely to lose money $84 \%$ of the time," National Edition, National Post, ISSN 14868008, 1999.

[4] J. Raymond, "Trading strategy development with technical \& fundamental analysis," PR Newswire Association LLC, New York 2012.

[5] E. Alexandr, Tradingem k bohatství, Praha: Grada Publishing a.s., 2006.
[6] V. Mařík, J. Lažanský, and O. Štěpánková, Umělá inteligence, Praha: Academia, ISBN 80-200-0502-1, 1993.

[7] I. Goldstein and S. Papert, "Artificial inteligence," Language and the Study of Knowledge, Cognitive Science, vol. 1, no. 1, 1977.

[8] J. Hančlová and L. Tvrdý, "Úvod do analýzy časových řad," Katedra Matematických Metod V Ekonomice, Ostrava, 2003.

[9] I. Taufer, O. Drábek, P. Seidl, "Umělé neuronové sítě - základy teorie a aplikace (1)," CHEMagazín č.4, ročník XV, pp. 32-34, 2005.

[10] Financnik.cz, Adaptive Builder - jak m.ǔže vypadat genetické generování obchodních system. (2009). dostupné z [Online]. Available: www.financnik.cz/komodity/recenze-sw/adaptrade-builder.html

[11] W. Cheng, B. McClain, and C. Kellly, "Artificial neural networks make their mark as a powerful tool for investors," Review of Businss, 1997.

[12] J. Williams, "Narrow-band analyzer," Ph.D. dissertation, Dept. Elect. Eng., Harvard Univ., Cambridge, MA, 1993.

[13] J. R. Coakley and C. E. Brown, "Artificial neura networks in accounting and finance: Modeling issues," International Journal of Intelligent Systems in Accountin, Finance and Managemen, vol. 9, no. 2, pp. 119, June 2000.

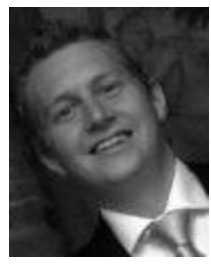

Jan Juricek was born in Prague, Czech Republic in 1980. Mr. Juricek graduated from the University of Economics in Prague, Faculty of informatics and statistics in major specialization of information management. Besides his PhD studying, he is currently working as a head of PMO in the business sector and is active in professional project management practices for 8 years. Mr. Juricek is the holder of the international certification for project management practices - @Prince2 Practitioner, is lecturing techniques of project management and is a member of professional associations for project management in Czech Republic. 